\title{
Impact of Hepatitis C Virus Infection on Cognitive Function in Patients With Covert Hepatic Encephalopathy
}

\author{
Farnaz Hashemi ${ }^{1}$; Ali Fathi Ashtiani ${ }^{2}$; Babak Mirminachi ${ }^{1}$; Maryam Sharafkhah ${ }^{1}$; Golnaz \\ Ekhlasi ${ }^{1}$; Elham Jafari ${ }^{1}$; Hossein Poustchi ${ }^{1, *}$ \\ ${ }_{1}^{1}$ Liver and Pancreatobiliary Diseases Research Center, Digestive Diseases Research Institute, Tehran University of Medical Sciences, Tehran, IR Iran

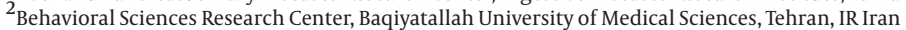 \\ *Corresponding Author: Hossein Poustchi, Liver and Pancreatobiliary Diseases Research Center, Digestive Diseases Research Institute, Tehran University of Medical Sciences, Tehran, \\ IR Iran. Tel: +98-2182415141, Fax:+98-2182415400, E-mail: h.poustchi@gmail.com \\ Received: June 7, 2015; Accepted: June 16, 2015
}

\begin{abstract}
Background: Liver cirrhosis has a significant impact on patient's quality of life and socioeconomic status and is associated with increased susceptibility to vehicle accidents and falls.

Objectives: This study was conducted to evaluate cognitive function in patients with cirrhosis.

Patients and Methods: All subjects, who underwent transient elastography (TE) between March 2014 and August 2014 in Shariati outpatient clinic, Tehran, Iran, were enrolled in the study. The diagnosis of cirrhosis was made based on clinical and laboratory findings and liver stiffness measurement (LSM) values $>14$. Wechsler Memory Scale (WMS) and simple visual reaction time (RT) were the neuropsychiatric tests used to assess cognitive function, in all subjects.

Results: A total of 37 cirrhotic patients and 37 matched controls were included. Patients with cirrhosis had significantly lower mean quotient (MQ) score, compared with controls ( $91 \pm 18.2$ vs. $114.6 \pm 17.5, \mathrm{P}<0.001$ ). All of WMS subscales, except associate learning, showed statistically significant differences between the two groups. Reaction time was more prolonged in patients with cirrhosis, compared with controls. Cognitive function of hepatitis $\mathrm{C}$ virus (HCV) patients was significantly impaired, with respect to logical memory, visual reproduction and $\mathrm{MQ}$ score, compared to other underlying causes of cirrhosis $(\mathrm{P}=0.01, \mathrm{P}=0.04$, and $\mathrm{P}=0.01$, respectively)

Conclusions: Our results suggested that neuropsychiatric and cognitive problems must be considered in the management of covert hepatic encephalopathy (HE) patients, especially in patients with HCV infection. The WMS and simple visual RT tests are useful methods for the early diagnosis of covert HE.
\end{abstract}

Keywords: Hepatic Encephalopathy; Liver cirrhosis; Cognition; Wechsler Scales; Reaction Time.

\section{Background}

Hepatic encephalopathy (HE) represents a major cause of morbidity and mortality in patients suffering from chronic liver diseases. It is characterized by serious neuropsychiatric and neurocognitive complications, including confusion, disorientation, ataxia and coma (1). A considerable percentage of patients with chronic liver diseases suffered from early stage of HE, known as covert HE (2). It is characterized by poor health-related quality of life, impaired daily functioning, poor socio-economic status, susceptibility to vehicle accidents and also, increased occurrence rate of overt HE, leading to increased mortality in patients with liver cirrhosis (3-8). Therefore, early diagnosis of psychosocial impairment is crucial in cirrhotic patients to prevent further progression and potential life threatening risk.

Currently, liver biopsy is the gold standard method for the detection of liver fibrosis; however, invasiveness is an important drawback in implementing this method, particularly in patients with early stages of liver fibrosis, as well as sampling error and variability in results interpretation (9). Liver stiffness measurement (LSM) by transient elastography is an easy-to-perform, non-invasive procedure, which represents a valuable screening method for early diagnosis of fibrosis in chronic liver diseases and also, liver transplantation patients (10-13).

There is no consensus regarding a gold standard test for early diagnosis of the neuropsychiatric changes, associated with minimal liver encephalopathy. Indeed, there are several confounding factors, which strongly affect patient's performance in neuropsychiatric tests, including age, gender, level of education and socioeconomic status. In addition, defining a cutoff point to clarify abnormal performance is difficult, due to heterogeneity of populations. Other factors, such as presence of psychiatric illnesses, other significant comorbidities and using interferon could alter the patient's performance on cognitive tests, making interpretation of results more difficult $(14,15)$.

Copyright ( 2015, Kowsar Corp. This is an open-access article distributed under the terms of the Creative Commons Attribution-NonCommercial 4.0 International License (http://creativecommons.org/licenses/by-nc/4.0/) which permits copy and redistribute the material just in noncommercial usages, provided the original work is properly cited. 
Hashemi F et al.

\section{Objectives}

The main purpose of this study was to evaluate cognitive function in patients with liver cirrhosis.

\section{Patients and Methods}

\subsection{Study Participants}

All subjects aged 25 and over, referring for liver elastography in Shariati outpatient clinic, Tehran, Iran, between March 2014 and August 2014, were invited to participate in the study. They received verbal information on the study and patients who accept to participate in this study gave their written consent. The study protocol was in accordance with the ethical guidelines of the 1975 Declaration of Helsinki. Patients, who accepted to participate in the study, underwent LSM and had a complete clinical evaluation and laboratory tests. The diagnosis of cirrhosis was established based on LSM findings (score $>14$ ), as well as clinical and laboratory findings. Patients presenting any of the following conditions were excluded: abdominal ascites, previous history of HE, hepatocellular carcinoma, any neurologic diseases such as Alzheimer's disease, Parkinson's disease and non-hepatic metabolic encephalopathies, current administration of psychoactive drugs, such as antidepressants or sedatives, alcohol and opium abuse and mental retardation. A total of 37 consecutive cirrhotic patients, with age, sex and education-matched healthy controls, were enrolled. This study was approved by the Ethics Committee of Digestive Disease Research Institute of Tehran University of Medical Sciences, Tehran, Iran.

\subsection{Cognitive Function Assessment}

All participants underwent Wechsler Memory Scale (WMS) test and simple visual reaction time (RT) test. The WMS is designed for assessing learning memory and working memory, which compromises of seven subsets: information, orientation, mental control, logic memory, digits forward and backward, visual reproduction and associate learning. The WMS provides a total "memory quotient" (MQ) that accounts for age-related mnemonic variability (16). Simple visual RT was determined by measuring the latency between presenting a visual stimulus and pressing a key, as the response, with the software designed on the basis of the World Health OrganizationNeurobehavioral Core Test Battery (17).

\subsection{Statistical Analysis}

Data were analyzed using IBM SPSS Statistics software package version 20 (IBM, New York, NY, USA). One-sample Kolmogorov-Smirnov test was used to estimate the distribution type of the data. Independent sample T-test was used to investigate the probable difference of quantitative variables between groups. Chi-squared test or Fisher's exact test were performed to evaluate the difference of categorical variables between groups, as indicated. One- way analysis of variance (ANOVA) test was used to investigate the probable differences of WMS subscales among cirrhotic patients with different underlying cause.

\section{Results}

Of 37 subjects, 21 (57\%) were male, with mean \pm SD age of $46.1 \pm 10.5$. Demographic features for patients and controls are summarized in Table 1 . The most common etiology of cirrhosis is hepatitis C virus (HCV) diagnosed in nine (25.7\%) patients, followed by autoimmune hepatitis in seven (20\%), hepatitis B virus (HBV) in six (16.2\%) and non-alcoholic steatohepatitis (NASH) in 10 (27\%). The cause of cirrhosis in five (13.5\%) subjects was unknown. Twenty-six (70.3\%) patients were categorized in ChildPugh A and 10 (27\%) patients in Child-Pugh B. We could not categorize one patient because of insufficient data. Two patients were excluded due to psychiatric comorbidities. There is a significant difference between two groups with respect to aspartate aminotransferase (AST), alanine aminotransferase (ALT), total bilirubin, prothrombin time, transient elastography (TE) score and controlled attenuation parameter (CAP) score (Table 1).

The MQ rate was significantly lower in patient group compared to control $(\mathrm{P}<0.001)$. The result for the subsets of WMS demonstrated that information $(P=0.02)$, orientation $(\mathrm{P}=0.01)$, mental control $(\mathrm{P}=0.001)$, logical memory $(<0.001)$, and visual reproduction $(\mathrm{P}=0.001)$ were significantly lower in cirrhotic patients, although, in case of associate learning, both groups showed similar results (Table 2). Comparing HCV cirrhotic subjects to other underlying cause of cirrhosis demonstrated that there is a significant impairment in logical memory, visual reproduction and $\mathrm{MQ}$ score $(\mathrm{P}=0.01, \mathrm{P}=0.04$, $\mathrm{P}=0.01$, respectively). However, when we compared all etiologies with each other, we did not find any statistically significant difference for all WMS subscales. Again, when we categorized etiology of cirrhosis based on viral and non-viral and put HBV and HCV in one group, comparing to other non-viral etiologies, cognitive impairment between these groups did not show any significant difference.

The results of simple RT were significantly better (faster) in control subjects compared to cirrhotic patients (483.4 \pm 188.8 vs. $371.2 \pm 79.8, \mathrm{P}=0.002)$. Furthermore, the number of errors was significantly higher in HCV patients compared to other groups $(\mathrm{P}=0.003)$

In the next step, the probable association between MQ score and BMI was investigated. There is a positive relationship between MQ score and BMI in cirrhotic patients ( $r=$ 0.054 , Figure $1 \mathrm{~A})$. On the other hand, this relation showed an inverse association in non-cirrhotic individuals ( $\mathrm{r}=$ -0.222 , Figure $1 \mathrm{~B}$ ). These relationships, however, were not statistically significant $(\mathrm{P}=0.75$ and $\mathrm{P}=0.18$, respectively).

Regarding the probable association between mean RT and BMI, both cirrhotic patients and non-cirrhotic individuals with higher BMI showed slower performance. $(\mathrm{r}=0.436, \mathrm{P}=$ 0.007 and $r=-0.069, P=0.68$, respectively) (Figure 2 ). 
Hashemi F et al.

Table 1. Demographic and Laboratory Features of the Patients and Controls a,b

\begin{tabular}{|c|c|c|c|}
\hline & Cirrhotic Patients & Non-Cirrhotic Controls & P Value \\
\hline Number, $\mathbf{n}$ & 37 & 37 & \\
\hline Age, y & $49.3 \pm 10.5$ & $46.2 \pm 9.6$ & 0.1 \\
\hline Gender & & & 0.8 \\
\hline Male & 22 & 21 & \\
\hline Female & 15 & 16 & \\
\hline BMI, $\mathrm{kg} / \mathrm{m}^{2}$ & $26.6 \pm 6.5$ & $25.5 \pm 4.9$ & 0.4 \\
\hline \multicolumn{4}{|l|}{ Level of education } \\
\hline Illiterate & $1(2.7)$ & $1(2.7)$ & \\
\hline Primary & $5(13.5)$ & $2(5.4)$ & 0.1 \\
\hline Secondary & $17(45.9)$ & $11(29.7)$ & \\
\hline Tertiary & $14(37.8)$ & $23(62.2)$ & \\
\hline \multicolumn{4}{|l|}{ Cirrhosis etiology } \\
\hline $\mathrm{HCV}$ & $9(24.3)$ & - & - \\
\hline HBV & $6(16.2)$ & - & - \\
\hline Autoimmune & $7(18.9)$ & $1(2.7)$ & - \\
\hline NASH & $10(27)$ & $28(75.7)$ & - \\
\hline Other & $5(13.5)$ & $8(21.6)$ & - \\
\hline AST, IU/L, median (range) & $97.8(20-232)$ & $31.2(8-111)$ & $<0.001^{\mathrm{C}}$ \\
\hline ALT, IU/L, median (range) & $94.9(13-364)$ & $45(12-120)$ & $0.002^{\mathrm{C}}$ \\
\hline ALP, U/L (range) & $368.7(53-2644)$ & $163.5(86-245)$ & $0.02^{\mathrm{C}}$ \\
\hline Albumin, g/dL (range) & $3.4(1.2-5)$ & $3.8(3-4.9)$ & 0.08 \\
\hline Total Bilirubin, mg/dL (range) & $1.5(0.5-4.4)$ & $0.9(0.4-1.8)$ & $0.001^{c}$ \\
\hline Prothrombin time, $s$ & $13.9(11.5-18.1)$ & $12.4(12-14.4)$ & $0.001^{c}$ \\
\hline TE scores, kPa & $33.9 \pm 19$ & $5.2 \pm 1.2$ & $<0.001^{\mathrm{C}}$ \\
\hline CAP Score & $232.6 \pm 52.8$ & $271.9 \pm 43.4$ & $0.001^{c}$ \\
\hline
\end{tabular}

a Abbreviations: ALT, alanine aminotransferase; ALP, alkaline phosphatase; AST, aspartate aminotransferase; BMI, body mass index; CAP, controlled attenuation parameter; HBV, hepatitis B virus; HCV, hepatitis C virus; kPa, KiloPascals; NASH; nonalcoholic steatohepatitis; TE, transient elastography.

$\mathrm{b}$ Data are presented as No. (\%) or Mean \pm SD.

c Statistically significant.

Table 2. Scores of Wechsler Memory Scale Subsets for the Patient and Control Groups ${ }^{\text {a }}$

\begin{tabular}{lccc}
\hline WMS Subsets & Cirrhotic Patients & Healthy Controls & P Value \\
\hline Information & $5.5 \pm 1$ & $5.9 \pm 0.2$ & $0.02^{\mathrm{b}}$ \\
Orientation & $4.6 \pm 0.7$ & $4.9 \pm 0.1$ & $0.01^{\mathrm{b}}$ \\
Mental control & $5.4 \pm 2.6$ & $7.3 \pm 1.8$ & $0.001^{\mathrm{b}}$ \\
\hline Logical memory & $6 \pm 2.7$ & $9.6 \pm 3.7$ & $<0.001^{\mathrm{b}}$ \\
\hline Digits forward and backward & $7.7 \pm 3.1$ & $10.4 \pm 2$ & $<0.001^{\mathrm{b}}$ \\
\hline Associate learning & $14.6 \pm 15.8$ & $16.4 \pm 4$ & 0.4 \\
Visual reproduction & $6.4 \pm 4$ & $9.2 \pm 3.1$ & $0.001^{\mathrm{b}}$ \\
\hline Memory quotient & $91 \pm 18.2$ & $114.6 \pm 17.5$ & $<0.001^{\mathrm{b}}$ \\
\hline
\end{tabular}

a Abbreviation: WMS, Wechsler Memory Scale.

b Statistically significant. 
A

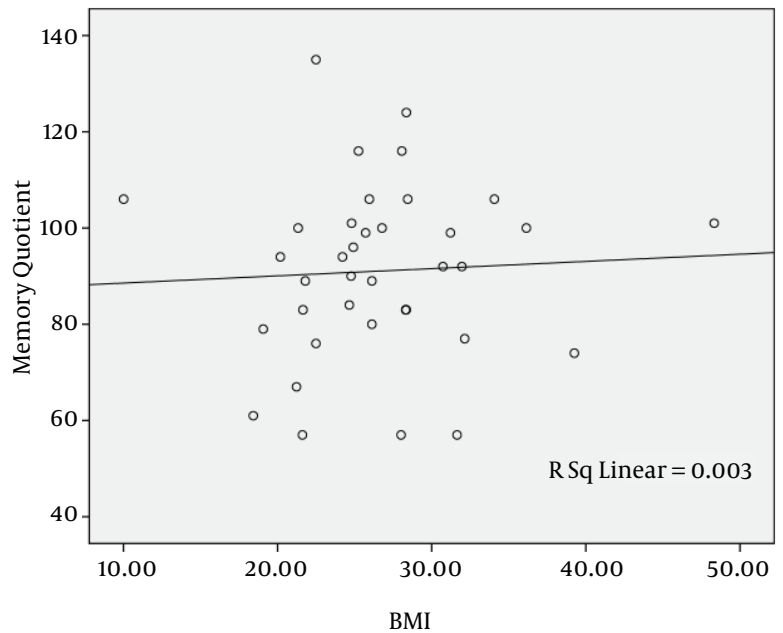

B

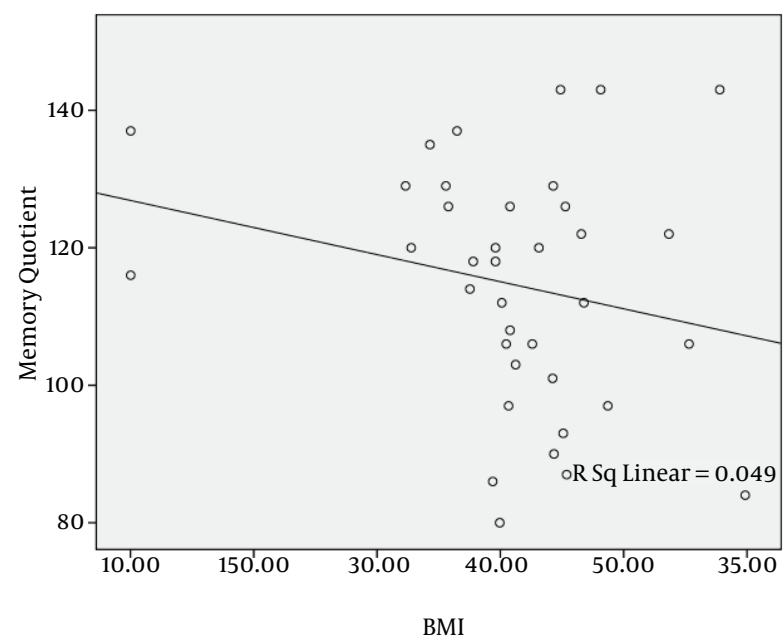

Figure 1. The Relationship Between Body Mass Index (BMI) and Memory Quotient (MQ) Score in A, Cirrhotic Patients and B, Non-Cirrhotic Individuals.

A

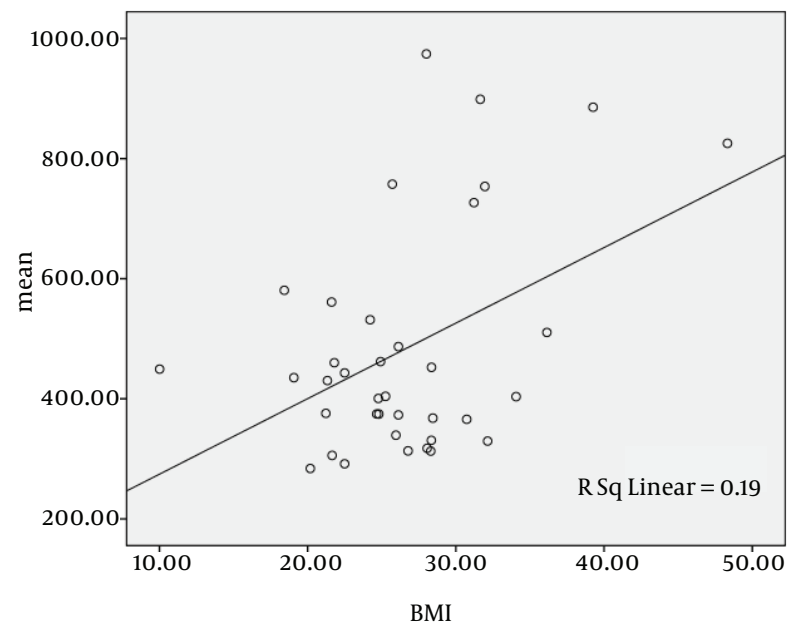

B

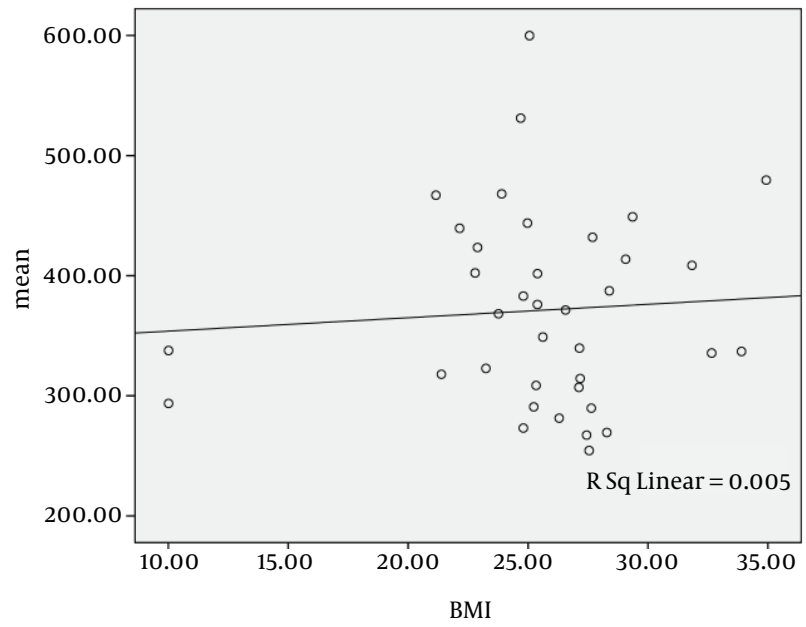

Figure 2. The Relationship Between Body Mass Index (BMI) and Mean Reaction Time in A, Cirrhotic Patients and B, Non-cirrhotic Individuals

\section{Discussion}

In this study, for the first time, neurocognitive function of patients with liver cirrhosis was evaluated by WMS and simple visual RT tests. Moreover, in previous studies regarding cognitive assessment of patients with covert HE, the diagnosis of cirrhosis was confirmed by liver biopsy; however, this is the first report in which TE was used to confirm the diagnosis.

Our findings are consistent with the previous studies, with respect to cognitive function alteration in patients with covert HE $(18,19)$. In WMS test, cirrhotic patients received an average score of $91 \pm 18.2$, while the control group had an average score of $114.6 \pm 17.5$. Therefore, this assessment reliably differentiates subjects in early stage of HE from non-cirrhotic subjects. Similar to WMS, simple visual RT test results are significantly different in cirrhotic patients, compared to healthy individuals. This test has a clear advantage over the other methods as it evaluates the visual and motor response and it appears reasonable that the test results are less influenced by confounding factors.

When we compared cognitive function among groups with different underlying etiology of cirrhosis, no significant association was observed. This finding is consistent with previous studies, indicating that cognitive function alteration was not significantly influenced by 
the underlying cause of liver cirrhosis (19-21). The association between chronic HCV infection and neuropsychiatric disorders, including cognitive impairment, has been shown in previous studies (22-24). Therefore, we categorized HCV patients, as one group, and compared their WMS subscale scores with other patients. As we expected, HCV patients' score on WMS test was significantly lower, with respect to logical memory, visual reproduction and MQ score. Drug abuse, using interferon and disease chronicity have been proposed by many authors, as responsible factors for this relationship (25, 26), while others believed that HCV directly involves the brain (27). In our study, all patients were newly diagnosed and were not current drug users and did not receive interferon therapy. This finding further supports the evidences of brain involvement in patients with HCV (27). Recently, it has been shown that HCV infection leads to impairment in the brain derived neurotrophic factor (BDNF) production (28). This factor, as the most abundant growth factor in the brain, has an important role in the regeneration and development of neuronal cells and is thought to be responsible in the pathogenesis of cognitive problems and mood disorders (29-31).

The negative relationship between MQ score and BMI, in non-cirrhotic subjects, was consistent with previous published studies $(32,33)$. Surprisingly, obesity has a paradoxical effect on cognitive function in our cirrhotic patients; higher BMI was associated with higher MQ score. This finding could be potentially explained by the fact that disease progression leads to weight loss, in liver cirrhosis, and patients with higher BMI are in a better clinical condition. This finding may be biased by the presence of abdominal ascites; however, most of our patients had an early stage of liver cirrhosis and did not developed ascites.

Our study has several limitations. First, our sample size is relatively small, which might affect the external validity of our results. Second, the assessment of cognitive function was applied in a non-blinded manner.

To summarize, our results demonstrated for the first time that cognitive function, in HCV patients, was more impaired compared to other underlying etiologies of cirrhosis. Therefore, neurocognitive evaluation must be especially considered in the management of patients with HCV infection. The WMS and simple RT tests are reliable methods for the early detection of HE in cirrhotic patients; however, larger studies are essential to determine cut-off values for these tests. In addition, TE could be a feasible and non-invasive procedure in order to screen general population and early diagnosis of apparently healthy patients suffering from early stages of chronic liver disease.

\section{Acknowledgements}

Special thanks are given to the staff of Digestive Diseases Research Institute, Tehran University of Medical Sciences, Tehran, Iran.

\section{Authors' Contributions}

Farnaz Hashemi: Study concept and design, acquisition of data; Ali Fathi Ashtiani: Critical revision of the manuscript for important intellectual content; Babak Mirminachi: Analysis and interpretation of data, drafting of the manuscript; Maryam Sharafkhah: Statistical analysis; Golnaz Ekhlasi: Administrative, technical, and material support; Elham Jafari: Administrative, technical, and material support; Hossein Poustchi: Study supervision.

\section{Funding/Support}

Authors give thanks for the financial support of Digestive Diseases Research Institute, Tehran University of Medical Sciences, Tehran, Iran.

\section{References}

1. Bajaj JS, Wade JB, Sanyal AJ. Spectrum of neurocognitive impairment in cirrhosis: Implications for the assessment of hepatic encephalopathy. Hepatology. 2009;50(6):2014-21.

2. Bajaj JS, Cordoba J, Mullen KD, Amodio P, Shawcross DL, Butterworth RF, et al. Review article: the design of clinical trials in hepatic encephalopathy-an International Society for Hepatic Encephalopathy and Nitrogen Metabolism (ISHEN) consensus statement. Aliment Pharmacol Ther. 2011;33(7):739-47.

3. Das A, Dhiman RK, Saraswat VA, Verma M, Naik SR. Prevalence and natural history of subclinical hepatic encephalopathy in cirrhosis. J Gastroenterol Hepatol. 2001;16(5):531-5.

4. Hartmann IJ, Groeneweg M, Quero JC, Beijeman SJ, de Man RA Hop WC, et al. The prognostic significance of subclinical hepatic encephalopathy. Am J Gastroenterol. 2000;95(8):2029-34.

5. Prasad S, Dhiman RK, Duseja A, Chawla YK, Sharma A, Agarwal R. Lactulose improves cognitive functions and health-related quality of life in patients with cirrhosis who have minimal hepatic encephalopathy. Hepatology. 2007;45(3):549-59.

6. Bajaj JS, Hafeezullah M, Hoffmann RG, Saeian K. Minimal hepatic encephalopathy: a vehicle for accidents and traffic violations. Am J Gastroenterol. 2007;102(9):1903-9.

7. Groeneweg M, Quero JC, De Bruijn I, Hartmann IJ, Essink-bot ML Hop WC, et al. Subclinical hepatic encephalopathy impairs daily functioning. Hepatology. 1998;28(1):45-9.

8. Bajaj JS, Riggio O, Allampati S, Prakash R, Gioia S, Onori E, et al. Cognitive dysfunction is associated with poor socioeconomic status in patients with cirrhosis: an international multicenter study. Clin Gastroenterol Hepatol. 2013;11(11):1511-6.

9. Regev A, Berho M, Jeffers LJ, Milikowski C, Molina EG, Pyrsopoulos NT, et al. Sampling error and intraobserver variation in liver biopsy in patients with chronic HCV infection. Am J Gastroenterol. 2002;97(10):2614-8.

10. Corpechot C, Carrat F, Poujol-Robert A, Gaouar F, Wendum D, Chazouilleres $\mathrm{O}$, et al. Noninvasive elastography-based assessment of liver fibrosis progression and prognosis in primary biliary cirrhosis. Hepatology. 2012;56(1):198-208.

11. Kim SU, Lee JH, Kim do Y, Ahn SH, Jung KS, Choi EH, et al. Prediction of liver-related events using fibroscan in chronic hepatitis B patients showing advanced liver fibrosis. PLoS One. 2012;7(5):e36676

12. Lemoine M, Katsahian S, Ziol M, Nahon P, Ganne-Carrie N, Kazemi $\mathrm{F}$, et al. Liver stiffness measurement as a predictive tool of clinically significant portal hypertension in patients with compensated hepatitis $\mathrm{C}$ virus or alcohol-related cirrhosis. Aliment Pharmacol Ther. 2008;28(9):1102-10.

13. Carrion JA, Navasa M, Bosch J, Bruguera M, Gilabert R, Forns X. Transient elastography for diagnosis of advanced fibrosis and portal hypertension in patients with hepatitis $C$ recurrence after liver transplantation. Liver Transpl. 2006;12(12):1791-8. 
14. Valentine AD, Meyers CA. Neurobehavioral effects of interferon therapy. Curr Psychiatry Rep. 2005;7(5):391-5.

15. BajajJS,Schubert CM, Heuman DM, Wade JB, Gibson DP, Topaz A, et al. Persistence of cognitive impairment after resolution of overt hepatic encephalopathy. Gastroenterology. 2010;138(7):2332-40.

16. Orangi M, Atefvahid MK, Ashayeri H. Standardization of the revised Wechsler memory scale in Shiraz. Iran J Psychiatry Clin Psychol. 2002;7(4):56-66.

17. Yazdi SM, Sharifian A, Dehghani-Beshne M, Momeni VR, Aminian O. Effects of fluoride on psychomotor performance and memory of aluminum potroom workers. Fluoride. 2011;44(3):158-62.

18. Ciecko-Michalska I, Wojcik J, Senderecka M, Wyczesany M, Binder M, Szewczyk J, et al. Cognitive functions in patients with liver cirrhosis: a tendency to commit more memory errors. Med Sci Monit. 2013;19:283-8.

19. Torres DS, Abrantes J, Brandao-Mello CE. Cognitive assessment of patients with minimal hepatic encephalopathy in Brazil. Metab Brain Dis. 2013;28(3):473-83.

20. Amodio P, Schiff S, Del Piccolo F, Mapelli D, Gatta A, Umilta C. Attention dysfunction in cirrhotic patients: an inquiry on the role of executive control, attention orienting and focusing. Metab Brain Dis. 2005;20(2):115-27.

21. Amodio P, Ridola L, Schiff S, Montagnese S, Pasquale C, Nardelli $\mathrm{S}$, et al. Improving the inhibitory control task to detect minimal hepatic encephalopathy. Gastroenterology. 2010;139(2):510-8.

22. Modabbernia A, Poustchi H, Malekzadeh R. Neuropsychiatric and psychosocial issues of patients with hepatitis $\mathrm{C}$ infection: a selective literature review. Hepat Mon. 2013;13(1):e8340.

23. Adinolfi LE, Nevola R, Lus G, Restivo L, Guerrera B, Romano $C$, et al. Chronic hepatitis $C$ virus infection and neurological and psychiatric disorders: an overview. World J Gastroenterol.
2015;21(8):2269-80.

24. Forton DM, Thomas HC, Murphy CA, Allsop JM, Foster GR, Main J, et al. Hepatitis $C$ and cognitive impairment in a cohort of patients with mild liver disease. Hepatology. 2002;35(2):433-9.

25. Foster GR. Quality of life considerations for patients with chronic hepatitis C. J Viral Hepat. 2009;16(9):605-11.

26. Foster GR, Goldin RD, Thomas HC. Chronic hepatitis C virus in fection causes a significant reduction in quality of life in the absence of cirrhosis. Hepatology. 1998;27(1):209-12.

27. Forton DM, Allsop JM, Main J, Foster GR, Thomas HC, Taylor-Robinson SD. Evidence for a cerebral effect of the hepatitis $C$ virus. Lancet. 2001;358(9275):38-9.

28. Modabbernia A, Ashrafi M, Keyvani H, Taslimi S, Poorkaveh A, Merat S, et al. Brain-derived neurotrophic factor predicts physical health in untreated patients with hepatitis C. Biol Psychiatry. 2011;70(5):e31-2.

29. Binder DK, Scharfman HE. Brain-derived neurotrophic factor Growth Factors. 2004;22(3):123-31.

30. Hashimoto K, Shimizu E, Iyo M. Critical role of brain-derived neurotrophic factor in mood disorders. Brain Res Brain Res Rev. 2004;45(2):104-14.

31. Chen R, Liang FX, Moriya J, Yamakawa J, Sumino H, Kanda T, et al. Chronic fatigue syndrome and the central nervous system. J Int Med Res. 2008;36(5):867-74.

32. Nguyen JC, Killcross AS, Jenkins TA. Obesity and cognitive decline: role of inflammation and vascular changes. Front Neurosci. 2014;8:375.

33. Cournot M, Marquie JC, Ansiau D, Martinaud C, Fonds H, Ferrieres J, et al. Relation between body mass index and cognitive function in healthy middle-aged men and women. Neurology. 2006;67(7):1208-14. 